\title{
Hospital Readmissions in a Community-based Sample of Homeless Adults: a Matched-cohort Study
}

\author{
Dima Saab, $M S c^{7}$, Rosane Nisenbaum, $\mathrm{PhD}, \mathrm{MS}^{7}$, Irfan Dhalla, MD, MSc ${ }^{1,2}$, and \\ Stephen W. Hwang, MD, MPH ${ }^{1,2}$
} ${ }^{1}$ Centre for Research on Inner City Health, Li Ka Shing Knowledge Institute at St. Michael's Hospital, Toronto, Ontario, Canada; ${ }^{2}$ Division of General
Internal Medicine, Department of Medicine, University of Toronto, Toronto, Ontario, Canada.

BACKGROUND: Hospital readmission rates are a widely used quality indicator that may be elevated in disadvantaged populations.

OBJECTIVE: The objective of this study was to compare the hospital readmission rate among individuals experiencing homelessness with that of a low-income matched control group, and to identify risk factors associated with readmission within the group experiencing homelessness.

DESIGN: We conducted a 1:1 matched cohort study comparing 30-day hospital readmission rates between homeless patients and low-income controls matched on age, sex and primary reason for admission. Multivariate analyses using generalized estimating equations were used to assess risk factors associated with 30-day readmission in the homeless cohort.

PARTICIPANTS: This study examined a cohort of 1,165 homeless adults recruited at homeless shelters and meal programs in Toronto, Ontario, between 6 December 2004 and 20 December 2005.

MAIN MEASURES: The primary outcome was the occurrence of an unplanned medical or surgical readmission within 30 days of discharge from hospital.

KEY RESULTS: Between 6 December 2004 and 31 March 2009, homeless participants $(\mathrm{N}=203)$ had 478 hospitalizations and a 30 -day readmission rate of $22.2 \%$, compared to 300 hospitalizations and a readmission rate of $7.0 \%$ among matched controls $(\mathrm{OR}=3.79,95 \% \mathrm{CI}$ 1.93-7.39). In the homeless cohort, having a primary care physician $(\mathrm{OR}=2.65$, $95 \%$ CI 1.05-6.73) and leaving against medical advice $(\mathrm{OR}=1.96,95 \% \mathrm{CI} 0.99-3.86)$ were associated with an increased risk of 30-day readmission.

CONCLUSIONS: Homeless patients had nearly four times the odds of being readmitted within 30-days as compared to low-income controls matched on age, sex and primary reason for admission to hospital. Further research is needed to evaluate interventions to reduce readmissions among this patient population.

Received September 15, 2015

Revised February 26, 2016

Accepted March 4, 2016

Published online May 19, 2016
KEY WORDS: hospital readmissions; homeless persons; administrative health data; matched-cohort.

J Gen Intern Med 31(9):1011-8

DOI: $10.1007 / \mathrm{s} 11606-016-3680-8$

(C) Society of General Internal Medicine 2016

\section{INTRODUCTION}

Unplanned readmissions to hospital are common and have been considered potential markers of incomplete treatment, inadequate coordination of health services following discharge, or other deficiencies in the quality of care. ${ }^{1-3}$ Hospital readmission rates are now a widely used performance indicator, both because readmissions are seen as being suboptimal from the patient perspective and because readmissions are costly. ${ }^{1}$ Homelessness is a common social problem in major urban centers. Individuals experiencing homelessness face a higher burden of illness than comparable housed individuals. ${ }^{4}$ Tuberculosis, HIV and hepatitis B and C are common, as are chronic conditions such as diabetes and hypertension. ${ }^{5}$ In addition, homeless adults face a high lifetime prevalence of mental illness and substance abuse. ${ }^{6}$ Due to high levels of chronic morbidity, inadequate living conditions, and barriers to obtaining appropriate outpatient care, patients who are homeless might be expected to have high readmission rates. ${ }^{4,7-9}$ These readmissions may pose a particular challenge for hospitals that serve communities with large populations of homeless individuals.

Few studies have examined readmission rates among patients who are homeless. A study by Kertesz and colleagues ${ }^{10}$ reported a 90-day medical/surgical readmission rate of $21.2 \%$ among homeless patients discharged from a single Boston hospital (they excluded pregnancy-related admissions). Buck and colleagues ${ }^{11}$ examined all-cause readmissions (including psychiatric admissions) among homeless patients and a random sample of housed patients in Harris County, Texas, and found that homeless individuals were twice as likely to be readmitted. Doran et al. ${ }^{12}$ observed a 30-day medical/ surgical readmission rate (excluding psychiatric admissions) of $50.8 \%$ among homeless patients at a single large hospital in a mid-sized northeastern U.S. city. The reasons for 
the substantially higher readmission rate observed in this study compared to the Boston study are unclear. They may be related to the fact that all participants in the Boston study had at least some contact with an outpatient health care program specifically designed to meet the needs of homeless individuals. ${ }^{12}$ Alternatively, it is possible that there are significant differences in the populations served between the two studies.

A different methodological approach to studying this issue is to examine hospitalizations in a representative community-based sample of homeless individuals, rather than identifying homeless patients who have been admitted to a particular hospital. This design would reduce the sampling bias that may result from studying a subgroup of the homeless population that presents to a single institution. Furthermore, readmissions should ideally be ascertained at all hospitals across a given region, rather than only at the hospital from which the patient was discharged. We therefore conducted this study of hospital readmissions in a cohort of homeless individuals in Toronto, Ontario, who were recruited at shelters and meal programs in the community. The first objective of this study was to determine the 30-day readmission rate of a representative sample of homeless adults in Toronto, compared to low-income controls matched for age, sex, and primary reason for admission to hospital. The second objective of this study was to identify risk factors associated with an increased odds of hospital readmission among homeless patients.

\section{METHODS}

\section{Homeless Participants}

This study examined a cohort of 1,165 homeless adults recruited at homeless shelters and meal programs in Toronto, Ontario, between 6 December 2004, and 20 December 2005. This cohort has been described previously. ${ }^{13}$ Homelessness was defined as residing in a shelter, public place, abandoned building, or vehicle, or staying temporarily with another person ('couch-surfing') within the previous seven days, and not having a place of one's own. Individuals who did not meet this definition of homelessness were excluded, as were those unable to provide consent or unable to communicate in English. Individuals who had never been issued an Ontario health insurance number were also excluded, because having a health insurance number was necessary for linkage to administrative health data. Participants were recruited at random from shelter lists and meal lines, and were screened to determine their eligibility and interest in participating in the study.

Of the 2,516 adults who were screened, 882 (35.1\%) were excluded from the study based on the following criteria: 229 (9\%) were not homeless based on our definition; 104 (4.1\%) were unable to communicate in English; 54 (2.1\%) were meal program users who had accessed shelter services in the previous week; 53 (2.1\%) could not provide informed consent; and $442(17.6 \%)$ did not possess valid health card numbers. In addition, 443 (17.6\%) of the individuals screened for the study declined to participate, and two records were found to be duplicates. The final sample size prior to linkage with administrative health data was 1,189 individuals. Homeless study participants were administered a comprehensive survey instrument focusing on factors related to health care utilization, such as demographic factors, history of homelessness, physical and mental health status, alcohol or drug use challenges, and health care need. These variables were assessed as risk factors for readmission among the homeless cohort. The survey allowed us to include variables that are not available through administrative health data alone.

\section{Administrative Health Data}

Study participants consented to having their Ontario health insurance number, name, date of birth, and sex linked to provincial administrative health data at the Institute for Clinical Evaluative Sciences. Administrative health data were obtained for 1,165 of 1,189 (98\%) participants: $94 \%$ of the sample had an exact match based on health insurance number and $4 \%$ had a probabilistic match based on first name, last name, date of birth and sex.

The administrative health data was used to identify hospital admissions and readmissions over the 5-year observation period (6 December 2004 to 31 March 2009). Length of stay was grouped into clinically meaningful categories. Discharge disposition was classified as death, routine discharge to home or other residence (including shelter or street), discharge against medical advice, or discharge to care (transfer to a continuing care or long-term care facility, hospice, addiction treatment center, or jail).

We excluded both psychiatric and pregnancy-related hospitalizations from our analytic data set, as we hypothesized that the mechanisms underlying these types of readmissions would differ from those underlying medical/surgical readmissions. We also excluded hospitalizations within 30-days of discharge if the admission was coded as elective.

\section{Matched Cohort Study Design}

Using a matched-cohort design, we matched each hospitalized homeless participant to a hospitalized low-income control residing in Toronto, with matching on the basis of age (within 10 years), sex and Case Mix Group (CMG) of the homeless participant's first hospitalization during the study period. The CMG classification system categorizes patients based on primary reason for admission to an acute-care hospital and complexity level (no complexity; complexity related to chronic conditions; complexity related to serious/important conditions; complexity related to potentially life-threatening conditions). ${ }^{14-16}$ For controls, low income was defined as residing in a census tract in Toronto with a mean household income in the lowest quintile. 
Of the 1,165 homeless participants, 220 were hospitalized at least once during the 5-year period. We attempted to match each of these 220 individuals to a low-income resident, but found no match for 17 of the homeless participants. Our matched-cohort was thus reduced to 203 homeless participants and 203 low-income controls.

\section{Primary Outcome}

The primary outcome was the occurrence of an unplanned medical or surgical readmission within 30 days of discharge from hospital. Admissions that occurred within 30 days of discharge following subsequent hospitalizations were also considered readmissions, meaning that a single individual could have multiple readmissions over the course of the study.

\section{Statistical Analysis}

Descriptive statistics were compared using Chi-square tests for categorical variables and Independent $t$-tests for continuous variables. The readmission rate was calculated as the proportion of hospitalizations that resulted in an unplanned 30-day readmission to an acute care hospital. We used the GENMOD procedure in SAS version 9.3 with a logit link function to estimate the odds ratio for the association between homelessness and 30-day readmission. This procedure uses generalized estimating equations to make adjustments for repeat hospitalizations by setting the individual as the cluster variable. Homelessness was represented by a binary variable that distinguished homeless participants from their matched lowincome controls.

The analytic dataset for the risk factors analysis included all hospitalizations $(n=504)$ and all readmissions $(n=108)$ that occurred among the initial homeless cohort $(\mathrm{N}=220)$, prior to matching to low-income controls. Risk factors were only assessed among the homeless cohort, since the equivalent variables were not available for the matched controls. We conducted multivariate analyses using generalized estimating equations to assess risk factors associated with readmission among the homeless cohort.

Variables included in the multivariate model were selected through an iterative process known as purposeful selection. ${ }^{17}$ Univariate logistic regressions with generalized estimating equations were conducted for each of the variables listed in Table 4. Variables that met the inclusion criteria of $p \leq 0.25$ at the univariate stage were included in the multivariate model (alongside age and demographic group, which were forced into the model). Variables were removed or retained if a) the variable had a $p \leq 0.10$, or $\mathrm{b}$ ) the parameter estimate of a remaining variable(s) changed by $15 \%$ or more upon its removal. Variables dismissed at the univariate stage were reintroduced back into the model to assess whether they had an effect in the multivariate model.

\section{Variable Definitions}

The following variables were used in our multivariate analyses. The age variable was categorized into clinically meaningful groups $(<25,26-39,40-49, \geq 50)$. Our demographic variable was comprised of three categories: single male, single female and family adult. This distinction between single adults and family adults (e.g. adults with dependent children) has been made in the homelessness literature, given that family adults tend to be a unique subgroup of the homeless population with fewer health care needs. ${ }^{13}$ Lifetime duration of homelessness was categorized into two groups: less than 2 years homeless versus 2 or more years homeless. Individuals with a history of traumatic brain injury were those who have had at least one injury to the head that left them "dazed, confused or disoriented." We used the Addiction Severity Index, which has been validated with homeless individuals, to assess for alcohol, drug or mental health problems. ${ }^{18,19}$ We used pre-established cutoff scores that are specific to the homeless population to dichotomize the problems into either absent or present. ${ }^{20}$ In addition, the following selfreported variables were dichotomized as absent or present: having a primary care physician; having unmet need for health care; and, having unmet need for mental health care.

Physical and mental health status were assessed using the physical component summary (PCS-12) and mental component summary (MCS-12) of the Short Form Health Survey (SF-12), which has been validated in homeless populations. ${ }^{21}$ Higher scores represent better health status. The selection of chronic health conditions was informed by the National Survey of Homeless Assistance Providers and Clients, and was categorized into four groups $(0,1,2$, and 3 or more conditions). ${ }^{20}$

We included characteristics of the hospitalization that are likely to influence readmission rates, such as length of stay, discharges against medical advice, and discharges to care. Using administrative data, we identified whether an individual left hospital against medical advice or was discharged to care. The latter includes individuals who were discharged to a continuing or long-term facility, or another location with supports (such as a hospice, an addiction treatment centre, or a jail). The length of stay (days) was categorized into clinically meaningful groups.

\section{RESULTS}

The characteristics of the homeless participants and lowincome controls and the characteristics of their first hospitalizations are shown in Table 1. The most common reasons for admission among the homeless participants were poisoning/ toxic effect of drugs, followed by pneumonia (Table 2). The 504 hospitalizations among the homeless cohort are described in Table 3.

Among the homeless participants who were successfully matched to a low-income control, there were 478 
Table 1 Characteristics of Homeless Participants and Controls and their First Hospitalizations

\begin{tabular}{|c|c|c|c|}
\hline Covariate & $\begin{array}{l}\text { Homeless } \\
\text { Participants } \\
(\mathbf{n}=\mathbf{2 0 3}) \\
\text { No. (\%) }\end{array}$ & $\begin{array}{l}\text { Low-Income } \\
\text { Controls } \\
(\mathbf{n}=\mathbf{2 0 3}) \\
\text { No. }(\%)\end{array}$ & $p$ value \\
\hline Age, years $($ mean $\pm S D)$ & $40.9 \pm 13.3$ & $40.9 \pm 13.2$ & N/A \\
\hline Sex & & & N/A \\
\hline Male & $122(60.1)$ & $122(60.1)$ & \\
\hline Female & $81(39.9)$ & $81(39.9)$ & \\
\hline $\begin{array}{l}\text { Hospital length of stay, } \\
\text { days }\end{array}$ & & & 0.13 \\
\hline$<2$ & $55(27.1)$ & $62(30.5)$ & \\
\hline 2 to 4 & 77 (37.9) & $79(38.9)$ & \\
\hline 5 to 9 & $35(17.2)$ & $42(20.7)$ & \\
\hline$\geq 10$ & $36(17.7)$ & $20(9.9)$ & \\
\hline $\begin{array}{l}\text { Left against medical } \\
\text { advice }\end{array}$ & $15(7.4)$ & $8(3.9)$ & 0.20 \\
\hline Discharge to care* & $19(9.4)$ & $10(4.9)$ & 0.12 \\
\hline
\end{tabular}

hospitalizations and 106 readmissions during the study period, corresponding to a crude readmission rate of $22.2 \%$. Among the low-income controls, there were 300 hospitalizations and 21 readmissions, corresponding to a crude readmission rate of $7.0 \%$ (Fig. 1). The majority of homeless participants (55\%) who did experience a readmission event were readmitted only once, and an additional $29 \%$ of individuals experienced two readmissions. The remaining $19 \%$ of homeless individuals experienced three or more readmissions. Among the lowincome controls, the vast majority ( $82 \%$ ) experienced only one readmission, $12 \%$ experienced two readmissions, and $6 \%$ experienced three or more readmissions.

Individuals with a history of homelessness had a significantly larger odds of being readmitted within 30 days as compared to the age-, sex- and CMG-matched low-income controls

Table 2. Most Common Case Mix Groups (CMG) for the First Hospitalization among Homeless Participants

\begin{tabular}{ll}
\hline \hline Case Mix Group & Frequency \\
\hline Poisoning/ Toxic Effect of Drug & 12 \\
Viral/ Unspecified Pneumonia & 9 \\
Inflammatory Disorder of Female Reproductive System & 6 \\
Chronic Obstructive Pulmonary Disease & 6 \\
Laparoscopic Cholecystectomy with/without Common & 6 \\
Bile Duct Exploration & 4 \\
Gastrointestinal Hemorrhage & 4 \\
Seizure Disorder, except Status Epilepticus & 4 \\
Symptom/Sign of Digestive System & 4 \\
HIV with Major Respiratory Complication/ Manifestation & 4 \\
Cellulitis & 3 \\
Ischemic Event of Central Nervous System & 3 \\
Arrhythmia without Cardiac Catheter & 3 \\
Syncope & 3 \\
Complex Hernia Repair & 3 \\
Fixation of Lower Limb except Ankle/Foot & 3 \\
Thyroid/Parathyroid/ Thymus Gland Intervention & 3 \\
Intracranial Intervention with Trauma/Complication & \\
of Treatment & 123 \\
All other Case Mix Groups & 203 \\
Total &
\end{tabular}

Table 3. Characteristics of Hospitalizations among Homeless Participants with and without an Unplanned Medical/Surgical Readmission within 30 days no. (\%)

\begin{tabular}{|c|c|c|c|}
\hline \multirow[b]{2}{*}{ Characteristic } & \multirow[b]{2}{*}{$\begin{array}{l}\text { Overall } \\
(n=504)\end{array}$} & \multicolumn{2}{|c|}{ Readmission within 30 days } \\
\hline & & $\begin{array}{l}\text { Yes } \\
(n=108)\end{array}$ & $\begin{array}{l}\text { No } \\
(n=396)\end{array}$ \\
\hline \multicolumn{4}{|l|}{ Predisposing Factors } \\
\hline Age & $40.9(13.3)$ & $\begin{array}{l}44.95 \\
(13.2)\end{array}$ & $39.3(13.2)$ \\
\hline \multicolumn{4}{|l|}{ Demographic Group } \\
\hline Single adult male & $289(57.3)$ & $55(50.9)$ & $234(59.1)$ \\
\hline Single adult female & $153(30.4)$ & $41(38.0)$ & $112(28.3)$ \\
\hline Family adult & $62(12.3)$ & $12(11.1)$ & $50(12.6)$ \\
\hline \multicolumn{4}{|l|}{$\begin{array}{l}\text { Lifetime duration of } \\
\text { homelessness }\end{array}$} \\
\hline$<2$ yrs & $214(42.5)$ & $36(33.3)$ & $178(45.0)$ \\
\hline$\geq 2$ yrs & $290(57.5)$ & $72(66.7)$ & $218(55.0)$ \\
\hline \multicolumn{4}{|l|}{ Race/ethnicity } \\
\hline White & $312(61.9)$ & $65(60.2)$ & $247(62.4)$ \\
\hline Black & $102(20.2)$ & $29(26.9)$ & $73(18.4)$ \\
\hline First Nations & $49(9.7)$ & $8(7.4)$ & $41(10.4)$ \\
\hline Other & $41(8.1)$ & $6(5.6)$ & $35(8.8)$ \\
\hline $\begin{array}{l}\text { History of traumatic } \\
\text { head injury }\end{array}$ & $290(57.5)$ & $72(66.7)$ & $219(55.3)$ \\
\hline $\begin{array}{l}\text { Alcohol problem in past } \\
30 \text { days }\end{array}$ & $156(31.0)$ & $25(23.2)$ & $131(33.1)$ \\
\hline $\begin{array}{l}\text { Drug problem in past } \\
30 \text { days }\end{array}$ & $184(36.5)$ & $28(25.9)$ & $156(39.4)$ \\
\hline $\begin{array}{l}\text { Mental health problem in } \\
\text { past } 30 \text { days }\end{array}$ & $199(39.5)$ & $48(44.4)$ & $151(38.1)$ \\
\hline \multicolumn{4}{|l|}{ Enabling Factors } \\
\hline $\begin{array}{l}\text { Has a primary care } \\
\text { physician }\end{array}$ & $445(88.3)$ & $103(95.4)$ & $342(76.9)$ \\
\hline Unmet need for health care & $75(14.9)$ & $22(20.4)$ & $53(13.4)$ \\
\hline $\begin{array}{l}\text { Unmet need for mental } \\
\text { health care }\end{array}$ & $45(9.0)$ & $6(5.6)$ & $39(9.9)$ \\
\hline \multicolumn{4}{|l|}{ Need Factors } \\
\hline PCS-12 Score (mean, SD) & $41.6(12.5)$ & $34.3(11.6)$ & $39.3(12.9)$ \\
\hline $\begin{array}{l}\text { MCS-12 Score } \\
\text { (mean, SD) }\end{array}$ & $40.1(12.8)$ & $41.5(10.8)$ & $40.2(12.5)$ \\
\hline \multicolumn{4}{|l|}{$\begin{array}{l}\text { Number of chronic } \\
\text { health conditions }\end{array}$} \\
\hline None & $118(23.4)$ & 29 (26.9) & $89(22.5)$ \\
\hline 1 & $106(21.0)$ & $15(13.9)$ & $91(23.0)$ \\
\hline 2 & $118(23.4)$ & $22(20.4)$ & $96(24.2)$ \\
\hline 3 or more & $162(32.1)$ & $42(38.9)$ & $120(30.3)$ \\
\hline \multicolumn{4}{|l|}{ Process of Care } \\
\hline \multicolumn{4}{|l|}{ Length of stay (days) } \\
\hline$<2$ & $117(23.2)$ & $21(19.4)$ & $96(24.2)$ \\
\hline 2 to 4 & $186(36.9)$ & $41(38.0)$ & $145(36.6)$ \\
\hline 5 to 9 & $106(21.0)$ & $26(24.1)$ & $80(20.2)$ \\
\hline$\geq 10$ & $95(18.9)$ & $20(18.5)$ & 75 (18.9) \\
\hline $\begin{array}{l}\text { Left against medical } \\
\text { advice }\end{array}$ & $47(9.3)$ & $16(14.8)$ & $31(7.8)$ \\
\hline Discharged to care & $67(13.3)$ & $11(10.2)$ & $56(14.1)$ \\
\hline
\end{tabular}

$(\mathrm{OR}=3.79,95 \%$ CI 1.93-7.39). Readmissions among the homeless participants $(n=106)$ occurred $0-7,8-14$ and 15-30 days after discharge in $45 \%, 23 \%$, and $32 \%$ of events, respectively. Corresponding percentages for readmissions among the low-income controls $(n=21)$ were $29 \%, 38 \%$, and $33 \%$. There was no significant difference in the distribution of the time of readmissions between the two groups $\left(\chi^{2}=2.82, p=0.24\right)$.

In the multivariate model, only two variables were found to be independently associated with hospital readmissions among the homeless patients (Table 4). First, individuals who left the hospital against medical advice had significantly 


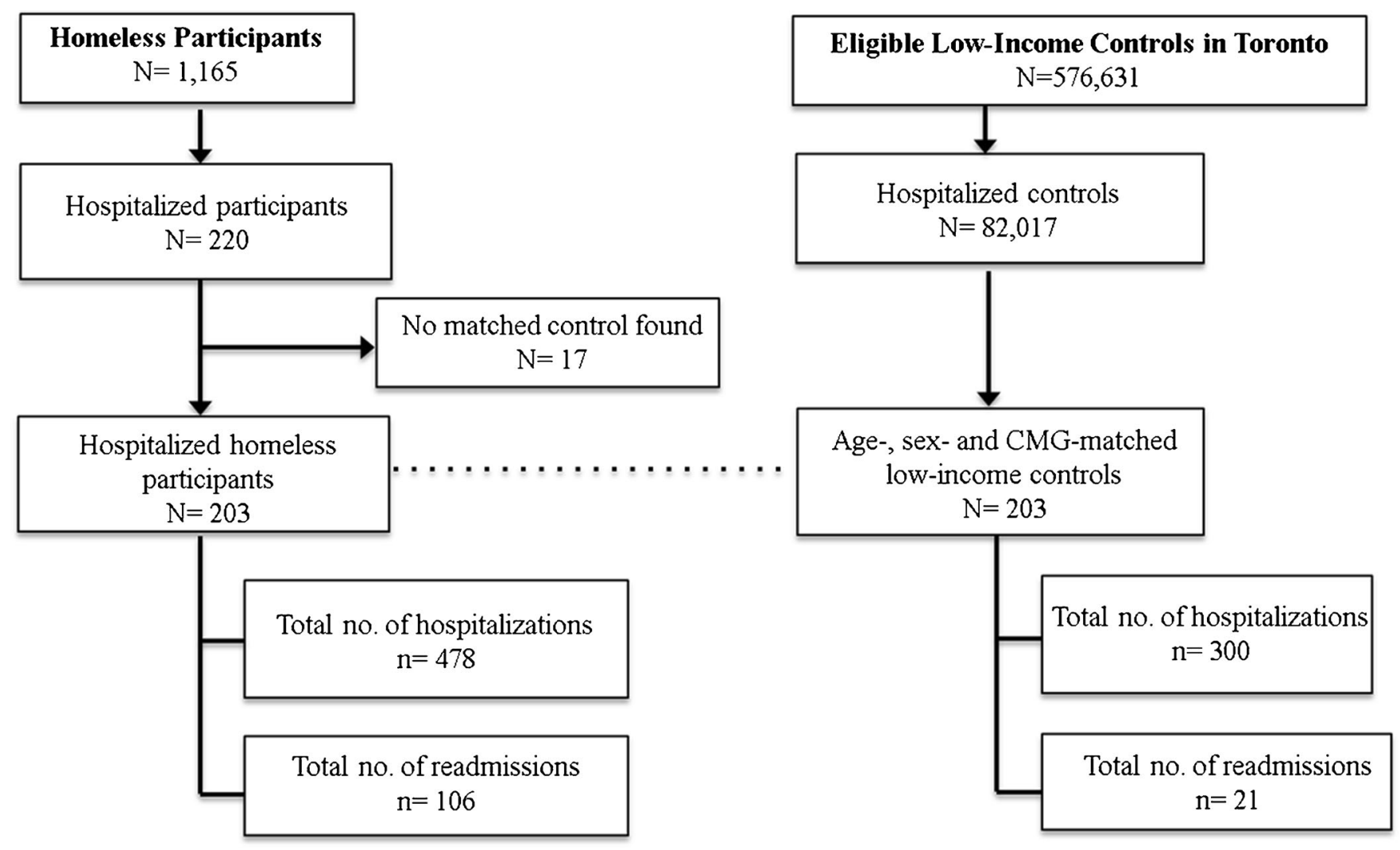

Figure 1. Flowchart of hospitalizations and 30-day readmissions among homeless participants and low-income controls. * Among these 220 homeless participants, there were a total of 504 hospitalizations and 108 readmissions within 30 days prior to matching to low-income controls (see Table 3 ).

larger odds of being readmitted compared to those who did not $(\mathrm{OR}=1.96,95 \%$ CI 0.99-3.86). Second, individuals who reported having a primary care physician had more than two and a half times the odds of being readmitted within 30 days as compared to those without a primary care physician $(\mathrm{OR}=2.65,95 \%$ CI 1.05-6.73).

\section{INTERPRETATION}

\section{Main Results}

Readmission rates have become accepted as a hospital performance indicator, particularly with the establishment of the Hospital Readmissions Reduction Program (HRRP) by the Patient Protection and Affordable Care Act (U.S), which ties compensation levels to the hospital's readmission rate. $^{22}$ As of October 2012, hospitals performing worse than the national risk-adjusted average for 30-day readmission for certain conditions will be penalized. In this context, hospitals have strong incentive to identify modifiable risk factors for readmission and to implement interventions that target patient populations at high risk of readmission. This study examined hospital readmissions in one such patient population.

Even after selecting for age and sex-matched low-income controls who had been hospitalized for the same conditions as the homeless participants, homeless patients still had nearly four times the odds of being readmitted within 30-days as compared to the controls. Furthermore, homeless patients who left hospital against medical advice were almost twice as likely to be readmitted compared to those who did not. Homeless participants who reported having a primary care physician were also more likely to be readmitted within 30 days as compared to those without a primary care physician.

\section{Related Studies}

We found readmission rates that are similar to those reported by Kertesz et al. ${ }^{10}(21.2 \%)$, but substantially lower than the rate $(50.8 \%)$ reported by Doran and colleagues. ${ }^{12}$ There may be several methodological and contextual reasons for these differences. Unlike our analyses (which excluded elective admissions), Doran et al. ${ }^{12}$ include both planned and unplanned 30-day readmissions. In addition, Doran's study was conducted at a hospital that appears to serve a particularly complex patient population, given that they reported a high readmission rate $(18.7 \%)$ even among their control group of general Medicaid patients. ${ }^{12}$ The high readmission rate reported by Doran et al. ${ }^{12}$ may also reflect fewer support services for homeless individuals residing in the study city, as compared to those that are available in Toronto and Boston. Other possible explanations are higher severity of illness among homeless individuals in the U.S. compared to Canada, due to lack of universal health insurance and poorer access to care for low- 
Table 4. Univariate and Multivariate Regression Model for Risk of Unplanned 30-day Medical/Surgical Readmission in the Homeless Cohort

\begin{tabular}{|c|c|c|c|c|}
\hline VARIABLE & $\begin{array}{l}\text { Univariate Regressions } \\
\text { OR and } 95 \% \text { CI }\end{array}$ & $p$ value & $\begin{array}{l}\text { Multivariate Model } \\
\text { OR and } 95 \% \text { CI }\end{array}$ & $p$ value \\
\hline \multicolumn{5}{|l|}{ Predisposing Factors } \\
\hline Age (years) & 1.00 & 0.91 & 1.00 & 0.94 \\
\hline \multicolumn{5}{|l|}{ Demographic Group } \\
\hline Single adult male (ref) & 1.00 & & 1.00 & \\
\hline Single adult female & $2.12(1.28-3.53)$ & 0.004 & $1.64(0.66-4.04)$ & 0.28 \\
\hline Family adult & $0.81(0.22-3.05)$ & 0.76 & $1.11(0.37-3.32)$ & 0.84 \\
\hline Lifetime duration of homelessness & $1.63(0.72-3.69)$ & 0.24 & & \\
\hline \multicolumn{5}{|l|}{ Race/ethnicity } \\
\hline White (ref) & 1.0 & & & \\
\hline Black & $1.51(0.41-5.58)$ & 0.54 & & \\
\hline Aboriginal & $0.74(0.31-1.76)$ & 0.50 & & \\
\hline Other & $0.65(0.22-1.91)$ & 0.43 & & \\
\hline Traumatic brain injury & $1.62(0.75-3.49)$ & 0.22 & & \\
\hline Alcohol problem & $0.61(0.27-1.35)$ & 0.22 & & \\
\hline Drug problem & $0.54(0.25-1.15)$ & 0.11 & & \\
\hline Mental health problem & $1.30(0.52-3.24)$ & 0.58 & & \\
\hline \multicolumn{5}{|l|}{ Enabling Factors } \\
\hline Has a primary care physician & $3.25(1.28-8.29)$ & 0.01 & $2.65(1.05-6.73)$ & 0.040 \\
\hline Unmet need for health care & $1.66(0.67-4.11)$ & 0.28 & & \\
\hline Unmet need for mental health care & $0.54(0.22-1.32)$ & 0.18 & & \\
\hline \multicolumn{5}{|l|}{ Need Factors } \\
\hline PCS-12 Score & $0.97(0.94-1.00)$ & 0.03 & $0.97(0.94-1.00)$ & 0.076 \\
\hline MCS-12 Score & $1.01(0.99-1.03)$ & 0.44 & $1.02(1.00-1.04)$ & 0.069 \\
\hline \multicolumn{5}{|l|}{ No. chronic conditions } \\
\hline None (ref) & 1.0 & & & \\
\hline 1 & $0.51(0.10-2.52)$ & 0.41 & & \\
\hline 2 & $0.70(0.17-2.91)$ & 0.63 & & \\
\hline 3 or more & $1.07(0.27-4.22)$ & 0.92 & & \\
\hline \multicolumn{5}{|l|}{ Process of Care } \\
\hline \multicolumn{5}{|l|}{ Length of stay (days) } \\
\hline$<2$ & 1.0 & & & \\
\hline 2 to 4 & $1.29(0.77-2.18)$ & 0.34 & & \\
\hline 5 to 9 & $1.49(0.72-3.05)$ & 0.28 & & \\
\hline$\geq 10$ & $1.22(0.58-2.56)$ & 0.60 & & \\
\hline Left against medical advice & $2.05(1.11-3.79)$ & 0.02 & $1.96(0.99-3.86)$ & 0.052 \\
\hline Discharged to care & $0.69(0.34-1.38)$ & 0.30 & & \\
\hline
\end{tabular}

*Bolded items are significant at a p value less than 0.05

income individuals. Buck and colleagues ${ }^{11}$ compared readmission rates among homeless patients to a random sample of housed adults from the same hospital district, and determined that patients who are homeless are at twice the risk of being readmitted. They do not report whether readmissions were planned or unplanned.

We found two variables that were independently associated with hospital readmission among the homeless cohort. Leaving hospital against medical advice has previously been found to be associated with an increased risk of readmission. ${ }^{23-25}$ In our study, a high proportion of hospitalized homeless participants left against medical advice (9.3\%), compared to the national average of $1.3 \%{ }^{26}$ In addition, having a primary care physician has previously been shown to be associated with an increased risk of readmission, possibly because having a physician may lead to earlier detection of clinical deterioration, and a lower threshold for referral to an emergency department. ${ }^{27}$ Regardless of the mechanism, it may be considered promising that patients who are most likely to be readmitted are connected to the health care system by their primary care physician. This suggests that primary care physicians could serve as the vehicle for interventions to reduce readmissions among patients who are homeless.

\section{Strengths and Limitations}

The analyses presented in this study benefitted from the use of both survey data obtained from in-person surveys and linkage to administrative health data. Unlike previous studies, hospital admissions and readmissions were identified using administrative health databases in a system with universal health insurance, allowing for the detection of all admissions to every acute care hospital in the entire province. Recruitment of participants in the community (rather than identification of patients as homeless at the time of admission) allows for a more representative sample of homeless individuals in which to assess readmission rates. In addition, we did not censor our data after the first readmission in order to more accurately reflect the health care utilization patterns of patients who are homeless. However, this study has certain limitations. Individuals without a health insurance number were excluded from this analysis, which resulted in the exclusion of persons who were refugees or had no legal status in Canada, as well as individuals who had recently moved to Ontario. As such, our study is not generalizable to these groups of individuals. In addition, controls were residents of low-income neighborhoods in Toronto, but individual-level data on the income level of controls were not available. It is also possible that 
some of the low-income controls may themselves have experienced homelessness during the observation period of the study. Participants were homeless at the time of recruitment, but their housing status was not known for the remainder of the observation period. Finally, our findings may overestimate readmission rates, since hospitals may have initiated greater efforts in recent years to address readmissions.

\section{CONCLUSION}

Given high levels of complexity, in combination with potentially inadequate discharge policies, patients who are homeless will likely require targeted interventions to mitigate their risk of readmission. Since individuals with a primary care provider were more likely to be readmitted, these care providers may be well positioned to address high readmission rates among their patients. Possible interventions may include asking all patients about their housing status, and connecting patients experiencing homelessness or at risk of homelessness to available community resources. With regards to hospitalized homeless patients, these individuals could be discharged to respite care, which has been found to be effective in reducing readmissions among this population, particularly when services are specifically targeted to the needs of individuals experiencing homelessness. ${ }^{10,28}$ Hospitals have been faced with the challenge of addressing readmission rates among the patients they serve. This becomes all the more difficult when poor health status is accompanied by a myriad of social and economic complexities, as with patients who are homeless. Further research is needed to evaluate interventions to reduce readmissions among this patient population with complex health care needs.

Acknowledgements: The authors wish to thank Randall Fransoo and Onil K. Bhattacharyya for their thoughtful feedback and suggestions.

Corresponding Author: Dima Saab, MSc; Centre for Research on Inner City HealthLi Ka Shing Knowledge Institute at St. Michael's Hospital, 30 Bond Street, Toronto, Ontario, Canada M5B 1W8 (e-mail: dima.saab@mail.utoronto.ca).

Compliance with Ethical Standards:

Funders: The study was supported by funding from the Agency for Healthcare Research and Quality (1 R01 HS014129-01) and the Canadian Institutes of Health Research (MOP-62736). This study was also supported by the Institute for Clinical Evaluative Sciences (ICES) and the Centre for Research on Inner City Health, which are funded by annual grants from the Ontario Ministry of Health and LongTerm Care. The funders had no role in the design and conduct of the study; collection, management, analysis, and interpretation of the data; and preparation, review, or approval of the article. The opinions, results, and conclusions reported in this article are the views of the authors and do not necessarily reflect the views of any of the abovenamed organizations. No endorsement by ICES or the Ontario Ministry of Health and Long-Term Care should be intended or inferred.

Prior Presentations: "re: Admissions among Toronto's Homeless Population". The Canadian Association of Health Services and Policy Research 2014 Annual Conference.

Conflict of Interest: The authors declare that they have no conflicts of interest.

\section{REFERENCES}

1. Friedman B, Basu J. The rate and cost of hospital readmissions for preventable conditions. Med Care Res Rev. 2004;61(2):225-240.

2. Halfon P, Eggli Y, Prêtre-Rohrbach I, Meylan D, Marazzi A, Burnand B. Validation of the potentially avoidable hospital readmission rate as a routine indicator of the quality of hospital care. Med Care. 2006;44(11):972-981

3. Kripalani S, LeFevre F, Phillips CO, Williams MV, Basaviah P, Baker DW. Deficits in communication and information transfer between hospitalbased and primary care physicians. JAMA. 2007;297(8):831-841.

4. Hwang Sw, Chambers C, Chiu S, Katic M, Kiss A, Redelmeier DA, et al. A comprehensive assessment of health care utilization among homeless adults under a system of universal health insurance. Am J Public Health. 2013; 103(S2):S294-S301.

5. Hwang SW, Dunn JR. Chapter 2: Homeless People. In: Galeo S, Vlahov D, eds. Springer; 2005. p. 19-41.

6. Goering P, Tolomiczenko G, Sheldon T, Boydell $\mathbf{K}$, Wasylenki D. Characteristics of persons who are homeless for the first time. Psychiatr Serv. 2002;53(11):1472-1474

7. Kushel MB, Vittinghoff E, Haas JS. Factors associated with the health care utilization of homeless persons. JAMA. 2001;285(2):200-206.

8. Mandelberg JH, Kuhn RE, Kohn MA. Epidemiologic analysis of an urban, public emergency department's frequent users. Acad Emerg Med. 2000;7(6):637-646.

9. Pearson DA, Bruggman AR, Haukoos JS. Out-of-hospital and emergency department utilization by adult homeless patients. Ann Emerg Med. 2007;50(6):646-652.

10. Kertesz SG, Posner MA, O'Connell JJ, Swain S, Mullins AN, Shwartz M, et al. Post-hospital medical respite care and hospital readmission of homeless persons. J Prev Interv Community. 2009;37(2): 129-142.

11. Buck DS, Brown CA, Mortensen K, Riggs JW, Franzini L. Comparing homeless and domiciled patients' utilization of the Harris County, Texas public hospital system. J Health Care Poor Underserved. 2012;23(4):1660-2670.

12. Doran KM, Ragins KT, Iacomacci AL, Cunningham A, Jubanyik KJ, Jenq GY. The revolving hospital door: hospital readmissions among patients who are homeless. Medical Care 2013.

13. Chambers C, Katic M, Chiu S, Redelmeier DA, Levinson W, Kiss A et al. Predictors of medical or surgical and psychiatric hospitalizations among a population-based cohort of homeless adults. Am J Public Health. 2013;103(S2):S380-S388.

14. Canadian Institute for Health Information. Canadian Hospital Reporting Project Technical Notes-Clinical Indicators. 2013.

15. Canadian Institute for Health Information. Discharge Abstract Database (DAD)/ CMG/Plx Data Quality: Re-Abstraction Study 2003: Accessed January 24, 2016.

16. Canadian Institute for Health Information. Case Mix Tools for Decision Making in Health Care. 1998:January 24, 2016.

17. Hosmer DW, Lemeshow S. Applied Logistic Regression. New York: Wiley; 2000.

18. Joyner LM, Wright JD, Devine JA. Reliability and validity of the Addiction Severity Index among homeless substance misusers. Subst Use Misuse. 1996;31:729-51.

19. Drake RE, McHugo GJ, Biesanz JC. The test-retest reliability of standardized instruments among homeless persons with substance use disorders. J Stud Alcohol. 1995;56:161-167.

20. Burt MR, Aron LY, Lee E. Homelessness: programs and the people they serve. Findings of the National Survey of Homeless Assistance Providers and Clients. 1999.

21. Larson CO. Use of the SF-12 instrument for measuring the health of homeless persons. Health Serv Res. 2002;37(3):733-750.

22. Centers for Medicare \& Medicaid Services. Readmissions Reduction Program. 2016:January 23, 2016.

23. Garland A, Ramsey CD, Fransoo R, Olafson K, Chateau D, Yogendran $\mathbf{M}$, et al. Rates of readmission and death associated with leaving hospital against medical advice: a population-based study. CMAJ. 2013;185(14): 1207-1214.

24. Choi M, Kim H, Gian H, Palepu A. Readmission rates of patients discharged against medical advice: a matched cohort study. PLoS One. 2011;6(9), e24459.

25. Hwang SW, Li J, Gupta R, Chien V, Martin RE. What happens to patients who leave hospital against medical advice? Can Med Assoc J. $2003 ; 168(4): 417-420$

26. Canadian Institute for Health Information. Leaving Against Medical Advice: Characteristics Associated with Self-Discharge. 2013. 
27. Hasan O, Meltzer DO, Shaykevich SA, Bell CM, Kaboli PJ, Auerbach AD, et al. Hospital readmission in general medicine patients: a prediction model. J Gen Intern Med. 2010;25(3):211-219.
28. Doran KM, Ragins KT, Gross CP, Zerger S. Medical respite programs for homeless patients: a systematic review. J Health Care Poor Underserved. 2013;24(2):499-524 